\title{
Drug release, cytocompatibility, bioactivity, and antibacterial activity of doxycycline loaded $\mathrm{Mg}-\mathrm{Ca}-\mathrm{TiO}_{2}$ composite scaffold
}

\author{
H.R. Bakhsheshi-Rad ${ }^{\text {a,*}}{ }^{\text {, E. Hamzah }}{ }^{\text {b }}$, Mark P. Staiger ${ }^{\text {c }}$, George J. Dias ${ }^{\text {d }}$, Z. Hadisi ${ }^{\text {e, M. Saheban }}{ }^{\text {a }}$, M. Kashefian ${ }^{\text {e }}$ \\ a Advanced Materials Research Center, Department of Materials Engineering, Najafabad Branch, Islamic Azad University, Najafabad, Iran \\ ${ }^{\mathrm{b}}$ Department of Materials, Manufacturing and Industrial Engineering, Faculty of Mechanical Engineering, Universiti Teknologi Malaysia, 81310 Skudai, Johor Bahru, Johor, Malaysia \\ c MacDiarmid Institute for Advanced Materials and Nanotechnology, Department of Mechanical Engineering, University of Canterbury, Private Bag 4800, Christchurch 8140, New Zealand \\ d Department of Anatomy, School of Biomedical Sciences, University of Otago, Dunedin 9054, New Zealand \\ e Biomaterials Group, Faculty of New Science and Technologies, University of Tehran, Tehran, Iran
}

\section{H I G H L I G H T S}

- $\mathrm{Mg}-\mathrm{Ca}-\mathrm{TiO}_{2}$ composite scaffold loaded with different concentrations of doxycycline were prepared by space holder method.

- Mg-based scaffold containing doxycycline possesses compressive strength of 5 MPa with porosities of $65 \%$.

- Antimicrobial activity of the composite scaffold increased with increasing doxycycline concentration.

- Mg-based composite scaffolds containing low concentrations of doxycycline showed good biocompatibility.

- These composite scaffolds showed good biological properties and desired drug release trend for bone infection treatment.

\section{A R T I C L E I N F O}

\section{Article history:}

Received 16 July 2017

Received in revised form 22 October 2017

Accepted 29 October 2017

Available online 31 October 2017

\section{Keywords:}

Mg composite scaffold

Drug delivery

Antibacterial activity

Biocompatibility

Bioactivity

\section{G R A P H I C A L A B STRACT}

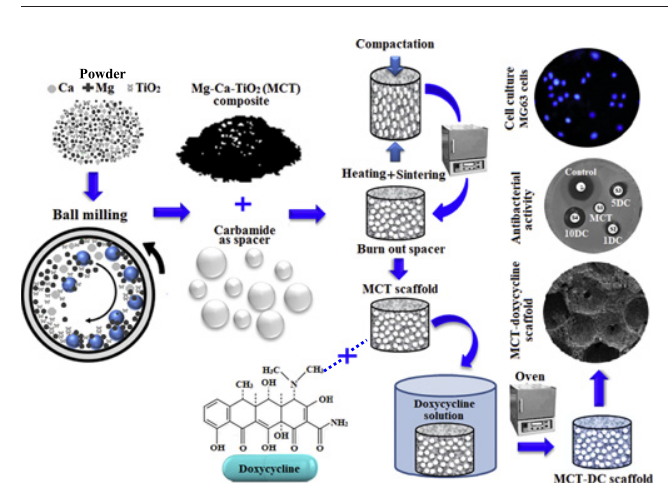

\begin{abstract}
A B S T R A C T
$\mathrm{Mg}-\mathrm{Ca}-\mathrm{TiO}_{2}$ (MCT) composite scaffolds loaded with different concentrations of doxycycline (DC) with a network of interconnected pores with good compressive strength $(5 \pm 0.1 \mathrm{MPa})$ were fabricated via space holder method for the first time. The results showed that MCT-DC scaffolds possess a porosity and pore size in the range of $65-67 \%$ and $600-800 \mu \mathrm{m}$ respectively. The bioactivity results exhibited the apatite formation on the MCT-DC scaffold surface, indicating that DC did not obstruct the bioactivity of MCT. The MCT-DC scaffolds drug release profiles show the initial burst and sustained drug release (55-75\%) and the release rate could be adjusted via altering the DC concentration. The MCT loaded with 1 and 5\% DC did not indicate cytotoxic behavior against MG63 cells while further DC loading resulted in some toxicity. Antimicrobial properties of MCT-DC scaffolds against Staphylococcus aureus (S. aureus) and Escherichia coli (E. coli) bacteria were examined and the results reveal oblivious inhibition zone around each MCT-DC scaffold whereas no obvious inhibition is observed around the MCT scaffold. Therefore, MCT-DC composite scaffolds with low concentration of DC could be alternative candidates for infection prevention and bone tissue engineering.
\end{abstract}

(c) 2017 Published by Elsevier Ltd.

\footnotetext{
* Corresponding author.

E-mail address: rezabakhsheshi@pmt.iaun.ac.ir (H.R. Bakhsheshi-Rad).
} 


\section{Introduction}

Porous scaffold has an important role in tissue engineering for bone reconstruction as it permits the growth of new human tissue and accelerates the healing process of the bone. Scaffolds were used for bone repair defects, cell adhesion and proliferation and also they can act as a platform for drug delivery [1-4]. Especially, metallic scaffolds have been considered for tissue engineering applications because of their appropriate mechanical properties. A number of metallic implant materials including titanium alloys, stainless steels, cobalt chromium alloys, zinc alloys, tantalum, nitinol, iron alloys, and magnesium alloys were generally used for biomedical applications $[1,5,6]$. Among these, $\mathrm{Mg}$ and it alloys have attracted considerable attention because their density is in the range of $\left(1.74-2.0 \mathrm{~g} / \mathrm{cm}^{3}\right)$ which is lower compared with the biomedical Co alloy (4.4-4.5 g/ $\left.\mathrm{cm}^{3}\right)$, Ti alloy $\left(4.4-4.5 \mathrm{~g} / \mathrm{cm}^{3}\right), \mathrm{Zn}$ alloy $\left(\sim 7.14 \mathrm{~g} / \mathrm{cm}^{3}\right)$, and iron alloy $\left(\sim 7.87 \mathrm{~g} / \mathrm{cm}^{3}\right)$ and is close to that of the natural bone $\left(1.8-2.1 \mathrm{~g} / \mathrm{cm}^{3}\right)[7,8]$. Mg alloys fracture toughness is higher compared with the ceramic biomaterials, whereas their Young modulus (41-45 GPa) is close to that of the bone which leads to the reduction of stress shielding effects [4,7]. Porous polymeric scaffolds most likely are not provided appropriate mechanical properties for bone replacement applications [9]. Chen et al. [10] reported that Mg-based alloys as better biodegradable materials for load-bearing applications due to their higher strength and ductility compared to the polymers. The above advantages of biodegradable Mg-based alloys led researchers to study porous Mg-based composites owing to their higher compressive strength and fracture toughness for bone replacement applications. Numerous examinations have pointed out that magnesium ions play an essential role in bone remodeling and development of musculoskeletal system [11,12]. Thus, magnesium has been used due to its biocompatibility, biodegradability, and bioactivity for biomedical applications. Currently, porous $\mathrm{Mg}$ scaffolds have received great attention for bone tissue engineering applications $[1,12,13]$. However, several issues should be addressed prior to consideration of porous Mg scaffolds for tissue engineering, most particularly their low corrosion resistance and high degradation rate which causes a serious and adverse inflammatory response along with cytocompatibility [5,14-16]. Therefore, mechanical alloying as a promising method has been applied to improve the biological corrosion resistance of magnesium [17]. In the present study, Mgbased composites were reinforced via addition of $\mathrm{Ca}$ and $\mathrm{TiO}_{2}$ with the aim of enhancement of the corrosion resistance of $\mathrm{Mg}$ scaffolds to meet the clinical requirements [17-19]. Calcium is a main element in human bone and improves bone healing process and its addition to $\mathrm{Mg}$ less than solid solubility limit could improve the corrosion resistance of $\mathrm{Mg}$ due to the cathodic secondary phases [20]. However, further addition of $\mathrm{Ca}$ to $\mathrm{Mg}$ (beyond the solubility limit) has a deleterious effect on the corrosion behavior. $\mathrm{TiO}_{2}$ as a biocompatible oxide with osteoconductive properties is also added to the matrix of the $\mathrm{Mg}$ based composite with the aim of improving corrosion properties [17, 21,22]. However, Mg-based composites presented poor antibacterial performance which result in implants associated with infections and lead to post-operative problems. The infection of bone is an essentially destructive problem with crucial clinical and economic effects [23,24]. It is explained as an inflammatory process which causes bone devastation generally attributed to the primary microbial infection, mostly through $S$. aureus bacteria $[3,23,25]$. To solve this problem, scaffolds were incorporated with antibiotics such as doxycycline (DC) as a glycopeptide antibiotic which is active against Gram-positive and Gramnegative bacteria and is able to inhibit the bacterial protein biosynthesis $[26,27]$. The incorporation of antibiotics such as DC [24] into Mg-based composite scaffold prevents the growth of bacterial cells and infection of the bone. Even though porous Mg-based composite scaffolds with interconnected porosities have a crucial role in growth of cells [1,2], a limited number of researches have been conducted so far regarding the fabrication and characterization of Mg-based composite as scaffolds. For example, porous Mg scaffold was fabricated via infiltrating the molten $\mathrm{Mg}$ into a $\mathrm{NaCl}$ preform accompanied by a subsequent leaching process [28]. In another study conducted by Staiger et al. [29] porous $\mathrm{Mg}$ scaffold was fabricated via negative salt-pattern molding process in three stages containing design of porous $\mathrm{Mg}$ via computer-aided design and then producing polymeric 3D template followed by sintering and infiltrating the molten magnesium. Other methods such as metal/gas eutectic unidirectional solidification, titanium wires as space holder, gel casting, polymeric sponge, and powder metallurgy (PM) methods have been applied to produce different types of porous $\mathrm{Mg}$ scaffolds [1,5]. Among these methods, powder metallurgy is the most common method consisted of a mixing of $\mathrm{Mg}$ powders with removable spacer following pressing them and subsequent sintering process, which has received great attention [5]. This can be due to the PM being cost-effective method having more control on the pore size, pores density and morphology as well as ability of near net shape production. In this context, Seyedraoufi et al. [15] synthesis of Mg-Zn scaffold via powder metallurgy (mixing of $\mathrm{Mg}$ and $\mathrm{Zn}$ with carbamide) and subsequent two-step heating process to burn out the carbamide particles $\left(250^{\circ} \mathrm{C}\right)$ and sintering the pow$\operatorname{der}\left(580^{\circ} \mathrm{C}\right)$. Their result revealed that the synthesis $\mathrm{Mg}-\mathrm{Zn}$ scaffolds containing $21-36 \%$ porosity exhibited higher mechanical properties comparable to the cancellous bone. However, fabrication and characterization of porous $\mathrm{Mg}-\mathrm{Ca}-\mathrm{TiO}_{2}$ (MCT) composite scaffold loaded with doxycycline with antibacterial properties has not been reported elsewhere. In the present study, space holder as a cost-effective method with ease of control on the morphology and size of pores has been employed to fabricate porous MCT composite scaffold loaded with DC to enhance antibacterial activity.

\section{Materials and methods}

Pure magnesium (purity $\geq 99 \%, 5-20 \mu \mathrm{m}$ particle size; SigmaAldrich), and calcium (99.5\% purity, particle size $<80 \mu \mathrm{m}$; SigmaAldrich) powders and titanium (IV) oxide ( $\mathrm{TiO}_{2}$, anatase nanopowder, purity $>99.7 \%,<100 \mathrm{~nm}$ particle size) which were supplied by SigmaAldrich, were used as the starting materials. The powder mixtures (Ca powders, $1 \mathrm{wt} \%$; $\mathrm{TiO}_{2}$ powders, $10 \mathrm{wt} \%$ and with the balance $\mathrm{Mg}$ powders) were dried in a vacuum dry oven at $220{ }^{\circ} \mathrm{C}$ for $10 \mathrm{~h}$ and were subsequently mixed using a planetary ball mill (Retsch, PM400, Germany) for $4 \mathrm{~h}$ in argon atmosphere. The detail of the ball-milling condition is summarized in Table 1 . The space holder method was subsequently applied to attain MCT scaffolds, throughout which the spherical carbamide $\left(\mathrm{CO}\left(\mathrm{NH}_{2}\right)_{2}\right.$; Merck, Germany) as the spacer with the particle size in the range of 600-800 $\mu \mathrm{m}$ and MCT nanopowder with a weight ratio of 70:30 were mixed. The powder was eventually pressed under $200 \mathrm{MPa}$ at a crosshead speed rate of $2.0 \mathrm{~mm} / \mathrm{min}$ in a cylindrical form with a size of $10 \mathrm{~mm}$ (diameter) $\times 15 \mathrm{~mm}$ (thickness) and preheated at $180^{\circ} \mathrm{C}$ for $2 \mathrm{~h}$ to burn out the spacer particles, and was subsequently sintered (HT04/17, Nabertherm, Germany) at $580^{\circ} \mathrm{C}$ for $2 \mathrm{~h}$ at a heating rate of $5{ }^{\circ} \mathrm{C} / \mathrm{min}$ in a furnace under the protection of argon gas. Doxycycline hyclate (DC; Sigma, St. Louis, MO) solutions were prepared by dissolving doxycycline powder $(10,50$, and $100 \mathrm{mg} / \mathrm{mL}$ and labelled as MCT-1DC, MCT-5DC and MCT-10DC) in distilled water. The loading process was carried out by applying 5 min vacuum before immersion of each MCT scaffold in the prepared DC solutions. The scaffolds were agitated on a roller shaker for $24 \mathrm{~h}$ and were then dried overnight by freeze dryer (FD-10, Pishtaz Engineering Co., Iran) according to the Ref. [25]. Schematic presentation of this method is shown in Scheme 1 . The faces of scaffold for SEM observations were mechanically ground down to 4000 grit SiC abrasive paper, and then, washed with distilled water and ultrasonically degreased in ethanol, and finally, etched in etched in the solution of $1 \mathrm{vol} \% \mathrm{HNO}_{3}, 75 \mathrm{vol} \%$ ethylene glycol and $25 \mathrm{vol} \% \mathrm{H}_{2} \mathrm{O}$. The interconnected and true porosity were calculated by using the method offered in Ref. [30], which was according to the Archimedes principle. The total porosity of the scaffolds consisted of 
Table 1

Mechanical alloying parameters adopted for milling MCT powder.

\begin{tabular}{ll}
\hline Parameter & Value \\
\hline Rotation speed & $300 \mathrm{rpm}$ \\
Ball-powder weight ratio & $10: 1$ \\
Vial and ball material & Zirconia \\
Mass of powder & $10 \mathrm{~g}$ \\
Milling time & $4 \mathrm{~h}$ \\
Capacity of vial & $125 \mathrm{~mL}$ \\
Diameter of the balls & $5 \mathrm{and} 10 \mathrm{~mm}$ \\
\hline
\end{tabular}

interconnected and closed pores according to the following equation:

True density $=\mathrm{wt} \%_{\mathrm{Mg}} \cdot \rho_{\mathrm{Mg}}+\mathrm{wt} . \%_{\mathrm{Ca}} \cdot \rho_{\mathrm{Ca}}+\mathrm{wt} . \%_{\mathrm{TiO}_{2}} \cdot \rho_{\mathrm{TiO}_{2}}$

Total porosity $=1-\frac{\mathrm{Wd}}{\rho(\mathrm{Wd}-\mathrm{Ws})} \times 100$

where $W_{d}, W_{s}$ and $\rho$ are the weight of the sample in air, the weight of the sample suspended in water, and true density of MCT $\left(1.987 \mathrm{~g} / \mathrm{cm}^{3}\right)$, respectively.

For compression test (Instron 5569, Norwood, MA, USA), cylindrical scaffolds ( $10 \mathrm{~mm}$, diameter $\times 15 \mathrm{~mm}$, height) were prepared and then compressive strength was measured using an universal testing machine at a crosshead speed of $0.5 \mathrm{~mm} / \mathrm{min}$ and a load cell of $10 \mathrm{kN}$ at room temperature.

The antibacterial activity of the MCT-DC scaffolds against Grampositive Staphylococcus aureus (S. aureus, ATCC 12600) and Gramnegative Escherichia coli (E. coli, ATCC 9637) bacteria was examined according to the disc diffusion antibiotic sensitivity and liquid medium microdilution techniques. The antibiotic gentamicin $(10 \mu \mathrm{g} / \mathrm{disc}$, Oxoid, UK) was employed as the positive control. The inhibition zone (IZ) around each specimen was assessed to figure out the antibacterial effect of the MCT-DC scaffolds [31]. An overnight culture of $E$. coli and $S$. aureus was diluted with broth medium to reach the absorbance value of $0.1-0.2$ at $625 \mathrm{~nm}$. Next, the samples ( $10 \mathrm{mg}$ ) were added to the obtained bacterial suspensions and incubated at $37^{\circ} \mathrm{C}$ with a gentle agitation rate of $100 \mathrm{rpm} / \mathrm{min}$ on a shaker platform. At 4 and $24 \mathrm{~h}$ time periods, the absorbance value of all tested solutions was read at $625 \mathrm{~nm}$ using a UV-vis spectrophotometer (Perkin Elmer Lambda 25 UV/Vis
Systems, USA). The bacterial inhibition percentage was determined by the following equation:

Bacterial inhibition $(\%)=\frac{\mathrm{I}_{\mathrm{C}}-\mathrm{I}_{\mathrm{S}}}{\mathrm{I}_{\mathrm{C}}} \times 100$

where $I_{C}$ is the absorbance value of the control bacterial suspension and $\mathrm{I}_{S}$ is the absorbance value of the bacterial suspension containing different samples each time.

For studying the in-vitro DC release of MCT-DC scaffolds, at first the samples were immersed in phosphate-buffered saline (PBS) and incubated at $37^{\circ} \mathrm{C}$. At each time point, $1 \mathrm{~mL}$ of the PBS solution containing the released DC was collected and restored by fresh PBS solution. The content of released DC was determined by ultraviolet-visible spectrophotometry based on the peak from $345 \mathrm{~nm}$ by making comparison with the standard calibration curve.

In order to evaluate bioactivity, MCT-DC scaffolds in the size of $15 \mathrm{~mm}$ (diameter) $\times 10 \mathrm{~mm}$ (height) were soaked in the simulated body fluid (SBF) solution for 7 days. Each scaffold was soaked in $100 \mathrm{~mL}$ of SBF and kept at $36.5 \pm 1{ }^{\circ} \mathrm{C}$ for the set period. After immersing in SBF, the immersed scaffolds were removed, rinsed gently with deionized water, and dried at ambient temperature.

The in vitro cytotoxicity of MCT-DC scaffolds was determined by indirect 3-(4,5-dimethylthiazol-2-yl)-2,5-diphenyltetra-zolium-bromide (MTT, Sigma, Saint Louis, USA) assay based on the extraction method. Briefly, the culture medium was added to the scaffolds ( $5 \mathrm{mg}$ ) and incubated at $37{ }^{\circ} \mathrm{C}$ for 1 and 2 days. 104 cells/mL were cultured on the 96well plates for $24 \mathrm{~h}$. Afterward, the cell medium was refreshed with 1 and 2-day extracts. The medium was removed after another $24 \mathrm{~h}$ and $100 \mu \mathrm{L}$ MTT agent $(0.5 \mathrm{mg} / \mathrm{mL}$ in PBS) was inoculated into each well and kept in the incubator for $4 \mathrm{~h}$. After $4 \mathrm{~h}, 100 \mu \mathrm{L}$ of DMSO (D2650, Sigma, Saint Louis, USA) was inserted to the well to dissolve the formazan crystals. Finally, the absorbance was read at $545 \mathrm{~nm}$ by using an ELISA Reader (Stat Fax-2100, Miami, FL, USA) and normalized by free scaffolds culture medium as a control group. Nuclear staining with DAPI (4', 6-diamidino-2-phenylindole, blue fluorescence in live cells) was performed in order to examine the MG63 cell proliferation on the MCT-DC scaffolds under fluorescence microscopy (Carl Zeiss, Germany).

As for electrochemical measurement, the MCT-TC scaffolds with a surface area of $1 \mathrm{~cm}^{2}$ were prepared to be measured by PARSTAT 2263

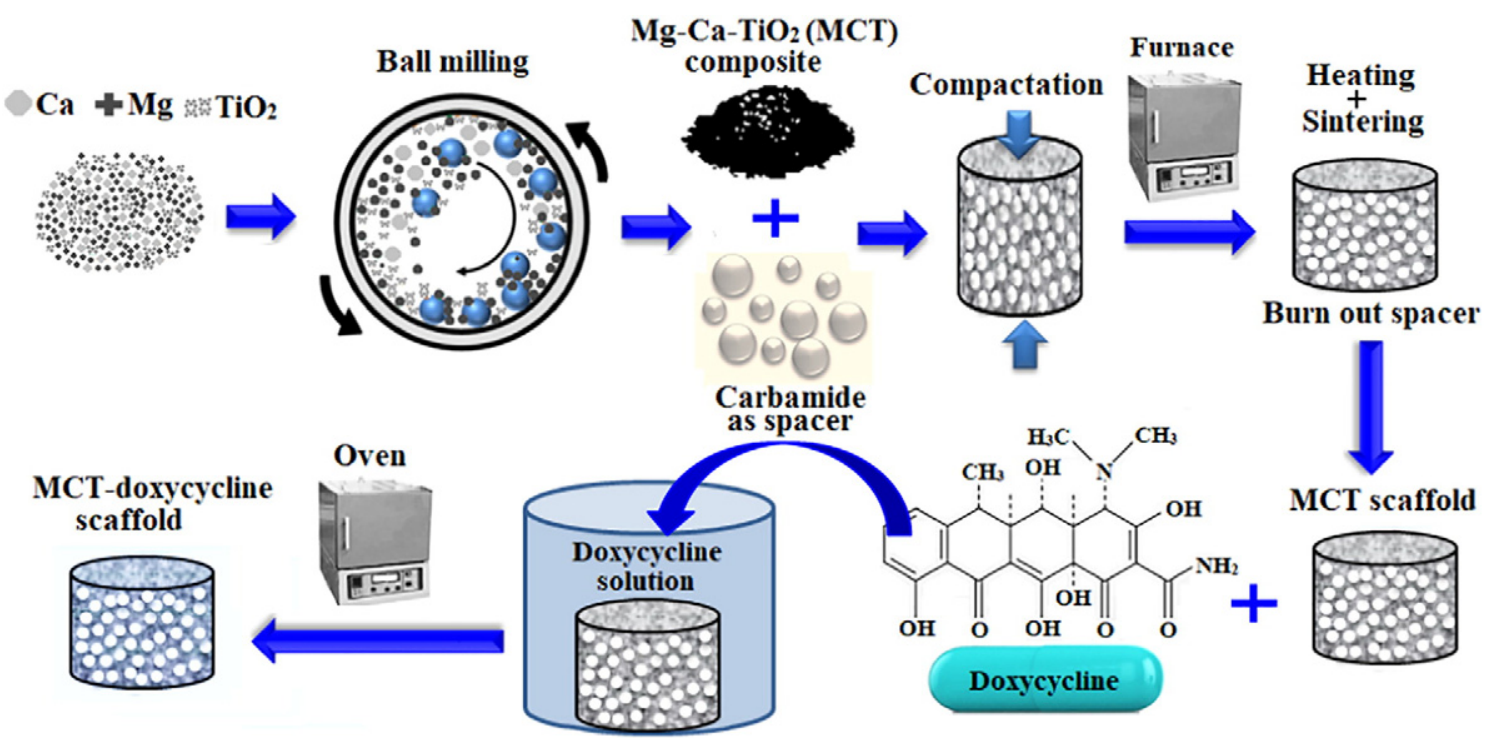

Scheme 1. A schematic of the space holder method for preparing MCT-DC composite scaffolds. 

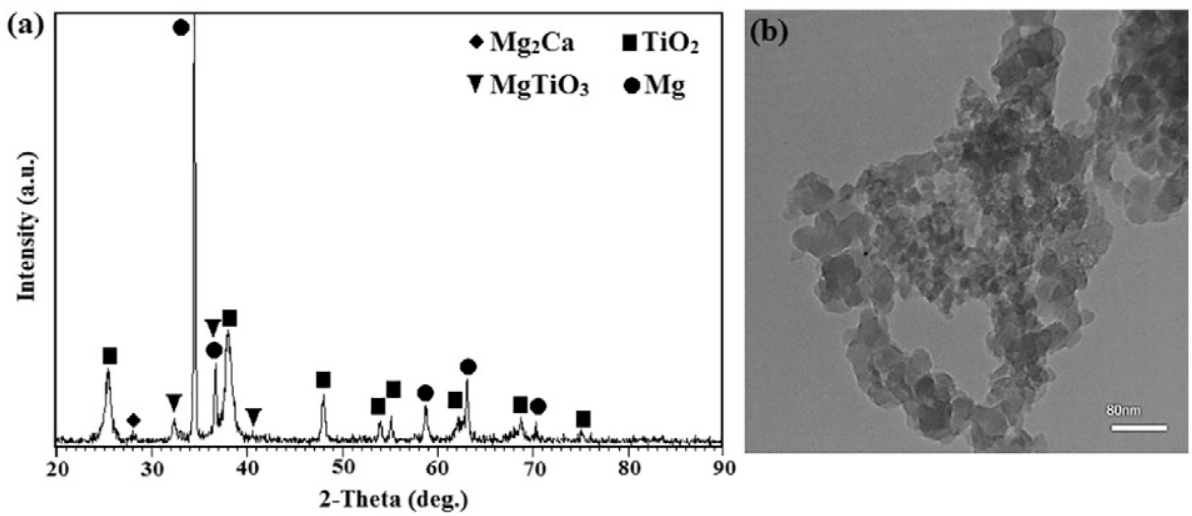

Fig. 1. XRD pattern (a), and TEM micrograph (b) of MCT nanopowders after $4 \mathrm{~h}$ milling.

potentiostat/galvanostat (Princeton Applied Research, 263A, Germany). They were submerged in a three-electrode cell filled with Kokubo SBF at $37^{\circ} \mathrm{C}$ and with a pH value of 7.44 to meet the requirements of Ref. [28].

Fourier-transform infrared (FTIR; ALPHA-T, Bruker, Ettlingen, Germany) spectrum was recorded in the spectral range of $4000-450 \mathrm{~cm}^{-1}$ to indicate the surface functional groups of MCT-DC scaffolds. Microstructures of MCT-DC scaffolds were studied using scanning electron microscopy (SEM, JEOL JSM-6380LA; Jeol Ltd., Japan, Tokyo) equipped with Oxford energy dispersive X-ray spectrometer (EDS) analysis with an operating voltage of $20 \mathrm{kV}$ and transmission electron microscopy (TEM, HT7700 Hitachi, Japan). An X-ray diffractometer (Siemens D5000, Karlsruhe, Germany) was used to determine the phase components through $\mathrm{Cu}-\mathrm{K} \alpha$ radiation $(45 \mathrm{kV}, 40 \mathrm{~mA}$ ) over the diffraction angles $(2 \theta)$ of $20-75^{\circ}$ at a scanning speed of $4^{\circ} / \mathrm{min}$. The crystallite size was measured using the Williamson-Hall method [32] based on the following equation:

$\frac{\beta}{2} \cot \theta=\frac{0.45 \lambda}{\operatorname{Sin} \theta \mathrm{D}}+\varepsilon$

where $\beta$ is the diffraction peak width at mid-height; $\lambda$ and $D$ are the $\mathrm{X}$-ray wavelength and the average crystallite size ( $\mathrm{nm}$ ), respectively; and $\varepsilon$ and $\theta$ are the microstrain and the Bragg diffraction angle, respectively.

\section{Results and discussion}

The XRD patterns of the MCT synthesis powder after $4 \mathrm{~h}$ milling are presented in Fig. 1a. The characteristic peaks of $\alpha-\mathrm{Mg}$ and $\mathrm{TiO}_{2}$ were found in the XRD patterns of the MCT synthesis powder whereas the presence of smaller peaks of $\mathrm{Mg}_{2} \mathrm{Ca}$ and geikielite $\left(\mathrm{MgTiO}_{3}\right)$ phases indicate the occurrence of mechanically induced self-propagating reactions (MSR) mechanism based on the following equation: $\mathrm{Mg}+1.5 \mathrm{TiO}_{2}$ $\rightarrow \mathrm{MgTiO}_{3}+0.5 \mathrm{Ti}$. In this context, Sul [33] revealed that the geikielite $\left(\mathrm{MgTiO}_{3}\right)$ is biocompatible and osteoconductive; thus, it is suitable for implant applications. According to the Williamson-Hall equation [32], the MCT crystallite size was in the range of $72 \mathrm{~nm}$. For further confirmation of structural evaluation including crystallite size and morphology of the MCT synthesis powder TEM analysis was performed. The TEM image (Fig. 1b) reveals that the particle size of the powders is in the range of 30-100 $\mathrm{nm}$. This is in agreement with the crystallite size of the synthesis powders calculated using the XRD data. In this respect, it was suggested [34] that the composite with a grain size $<100 \mathrm{~nm}$ presented better mechanical and biological properties.

The entire FT-IR spectra (Fig. 2) showed the characteristic peaks of MCT composite scaffold including the peak in the range of $900-400 \mathrm{~cm}^{-1}$, which is attributed to the Ti-O-Ti stretching [35]. The Ti- 0 bands were observed at $1395 \mathrm{~cm}^{-1}$, while the band at $1627 \mathrm{~cm}^{-1}$ was related to the $\mathrm{O}-\mathrm{H}$ bands [36]. The band at
$1083 \mathrm{~cm}^{-1}$ and $3696 \mathrm{~cm}^{-1}$ can be assigned to $\mathrm{Mg}$ - $\mathrm{O}$ stretching vibration. The MCT-DC composite scaffolds presented the characteristic peaks of DC at 3388,3000 , and $2950 \mathrm{~cm}^{-1}$ which are related to $\mathrm{OH}$, $\mathrm{N}-\mathrm{H}$, and $\mathrm{C}-\mathrm{H}$ stretching vibrations, respectively $[37,38]$. The bands at 1745 and $1451 \mathrm{~cm}^{-1}$ are attributed to the amide $(\mathrm{N}-\mathrm{H})$ bending and aromatic $\mathrm{N}-\mathrm{H}$ bending vibrations, respectively. Multiple peaks between 1400 and $1700 \mathrm{~cm}^{-1}$ are related to aromatic $\mathrm{C}=\mathrm{O}$ and $\mathrm{C}=\mathrm{C}$ stretching $[37,38]$. Furthermore strong peak at $1557 \mathrm{~cm}^{-1}$ related to the aromatic $\mathrm{N}-\mathrm{H}$ bending. In addition, the bands at 1082 and $846 \mathrm{~cm}^{-1}$ belong to $-\mathrm{CH}_{2}$ and $\mathrm{C}-\mathrm{H}$ bending vibrations, respectively [39].

The SEM images of MCT and MCT-DC composite scaffolds containing 1,5 and $10 \%$ doxycycline exhibited (Fig. 3 ) the formation of porous scaffolds consisted of interconnected porosity with pore sizes ranging from 600 to $800 \mu \mathrm{m}$. In this respect, it was suggested that the scaffold should possess an interconnected porous structure besides its porosity size $(>300 \mu \mathrm{m}$ ) for better cell seeding and the growth of tissue [1,2]. It was also visible that due to the evolution of carbon dioxide gas, macro pores with pore sizes ranging from 100 to $250 \mu \mathrm{m}$ were produced (indicated by arrow). In this respect, Roohani et al. [2] showed that the presence of micro-pores is crucial since they are required for capillary ingrowth and cell-matrix interactions. As can be seen, by increasing the concentration of doxycycline, no substantial difference in the pores size was detected. This indicates that the amount of porosity did not depend on the composition of the scaffolds. It is noteworthy that the MCTDC composite scaffolds possess an average total porosity of 65-67\% with a spherical pore morphology which is homogenously distributed. This implies that carbamide as the spacer agent possesses the particle size

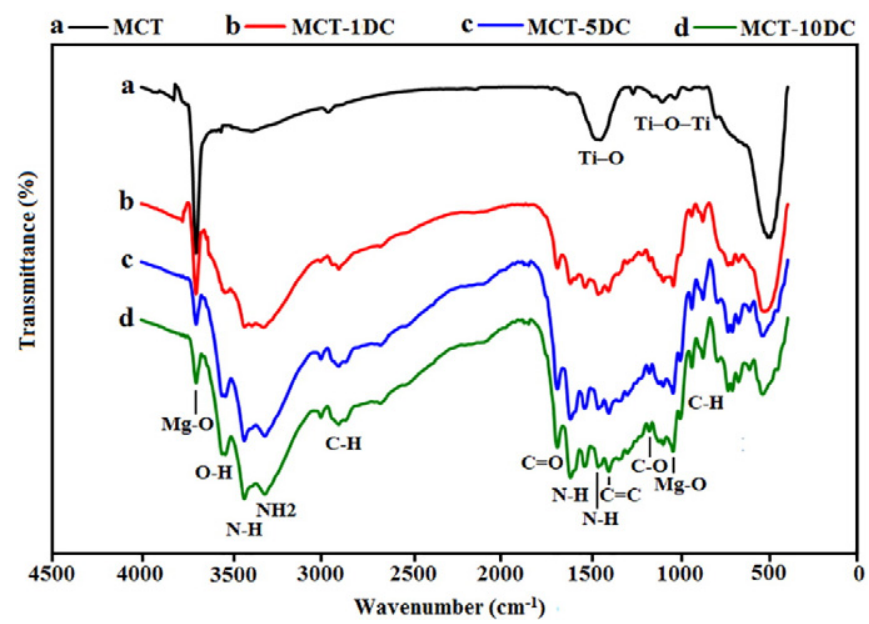

Fig. 2. FTIR absorption spectra of MCT (a) and MCT-DC composite scaffolds with various doxycycline concentrations of (b) 1, (c) 5, and (d) $10 \%$. 

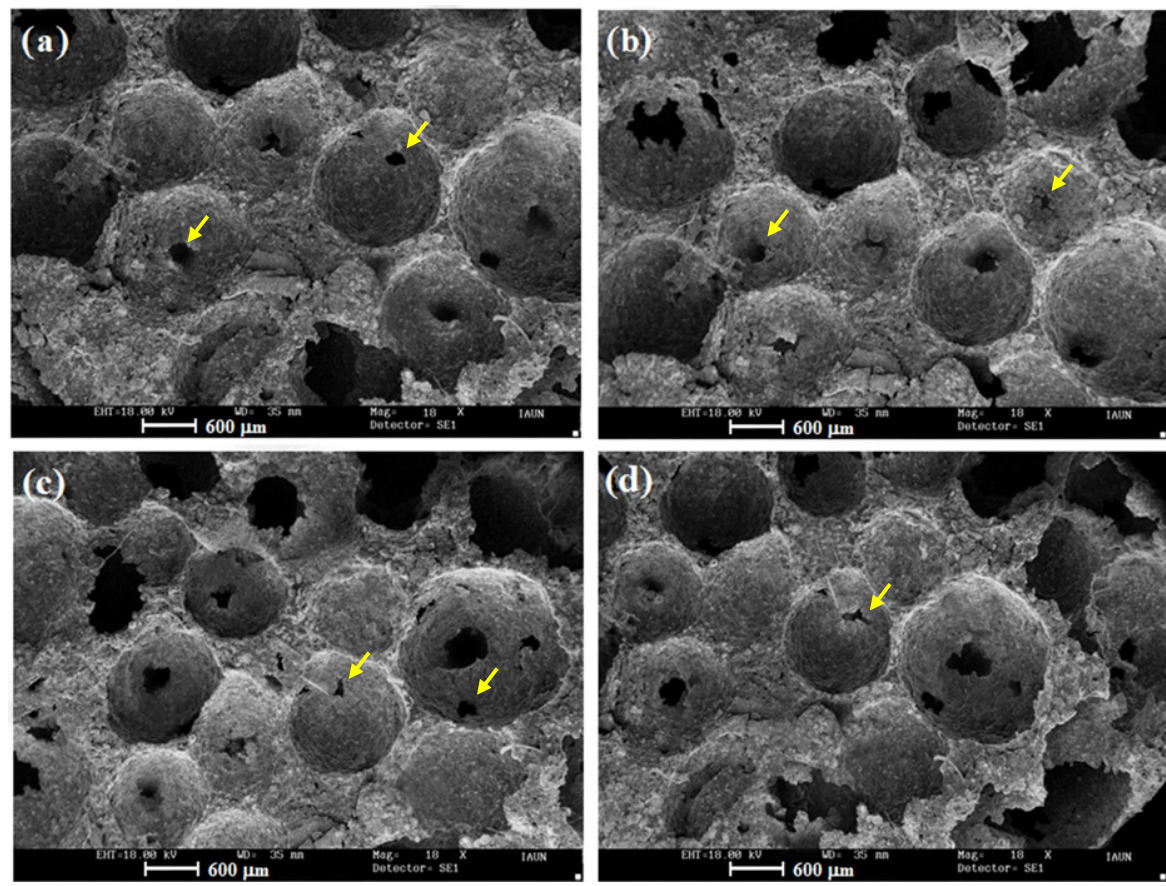

Fig. 3. SEM images of MCT (a) and MCT-DC scaffolds with various doxycycline concentrations of (b) 1 , (c) 5 , and (d) $10 \%$

of $600-800 \mu \mathrm{m}$ and these particles are able to maintain their initial round-like shapes throughout the fabrication procedure. Some necks with the size of 100-200 $\mu \mathrm{m}$ between the pores were also observed in approximately $50 \%$ of the pores in the cross section (Fig. 3d), implying a good level of interconnectivity [40].

The potentiodynamic polarization curves of pure $\mathrm{Mg}, \mathrm{MCT}$, and MCT-DC composite scaffolds in SBF at $37{ }^{\circ} \mathrm{C}$ are shown in Fig. 4a. The corrosion potential ( $\mathrm{E}_{\text {corr }}$ ) of pure $\mathrm{Mg}$ is $-1845 \pm 13 \mathrm{mV}_{\mathrm{SCE}}$ and shifts to nobler direction $\left(-1733 \pm 11 \mathrm{mV}_{\mathrm{SCE}}\right)$ after addition of $\mathrm{Ca}$ and $\mathrm{TiO}_{2}$ to the $\mathrm{Mg}$ scaffold. The corrosion density ( $\mathrm{i}_{\text {corr }}$ ) of MCT scaffold $\left(210.7 \pm 10 \mu \mathrm{A} \cdot \mathrm{cm}^{-2}\right)$ is low compared with the pure Mg scaffold $\left(40.6 \pm 3 \mu \mathrm{A} \cdot \mathrm{cm}^{-2}\right)$. This is attributed to the existence of a small content of $\mathrm{Ca}$ in the composite scaffold which could stabilize brucite, $\mathrm{Mg}(\mathrm{OH})_{2}$, and the aforementioned phase (brucite) can act as a protective layer which slows down the penetration of SBF into the substrate, hence interrupting the direct interface with the Mg alloy. However, MCT-DC scaffolds loaded with different concentrations of DC show a similar $\mathrm{E}_{\text {corr }}$ and $\mathrm{i}_{\text {corr }}$, indicating a less significant change observed in degradation rate with increasing DC from 1 to $10 \%$.

Prior to obtaining the probability to failure of the whole dataset of MCT-DC composite scaffolds, it was essential to confirm that the addition of doxycycline had no significant effect on the compressive strength. According to the preliminary conclusion, the influence of doxycycline on the compressive strength of MCT-DC composite scaffold was negligible. This is due to the fact that no considerable difference in the size and shape of the porous MCT scaffolds was found after the incorporation of DC into the MCT scaffold. As can be seen in Fig. 4b, the stress-strain curve of the MCT-DC scaffolds composed of three specific regions including linear elastic (region 1) which is increased to the highest compressive strength. Afterward, with increasing the stress, the entire pores walls were collapsed (region 2), and finally densification of the collapsed scaffold occurred via more escalating the stress. These results are in good agreement with those reported by Ghomi et al. [30]. The compressive strength of MCT-DC scaffolds consisting of $0,1,5$ and $10 \%$ doxycycline is in the range of $5 \pm 0.1 \mathrm{MPa}$. It was also reported [30] that the scaffolds containing carbamide as the spacer presented higher compressive strength than those containing sodium chloride as the spacer as a result of the presence of lower porosity and pore size.

The in vitro drug release property of MCT-DC scaffolds was evaluated by dipped of DC loaded scaffolds into the PBS solution $(\mathrm{pH}=7.4)$ at $37^{\circ} \mathrm{C}$. In Fig. 5, both burst and sustained cumulative release mechanisms can be seen. Moreover, all samples showed similar release profiles with slight differences in the amount of released DC. MCT-1DC and MCT10DC scaffolds showed the lowest $(34.3 \pm 0.6 \%)$ and highest $(37.2 \pm$ $0.3 \%$ ) burst release during the first $3 \mathrm{~h}$, followed by sustained release
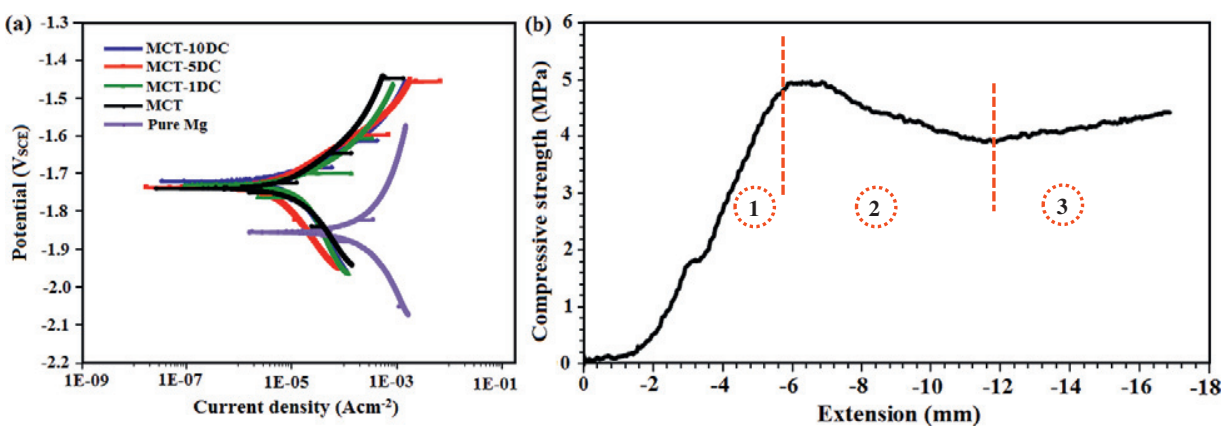

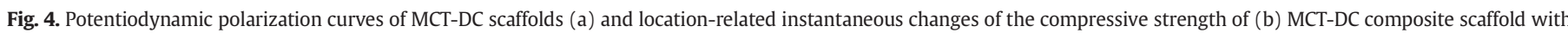
$65 \mathrm{vol} \%$ carbamide as the spacer. 


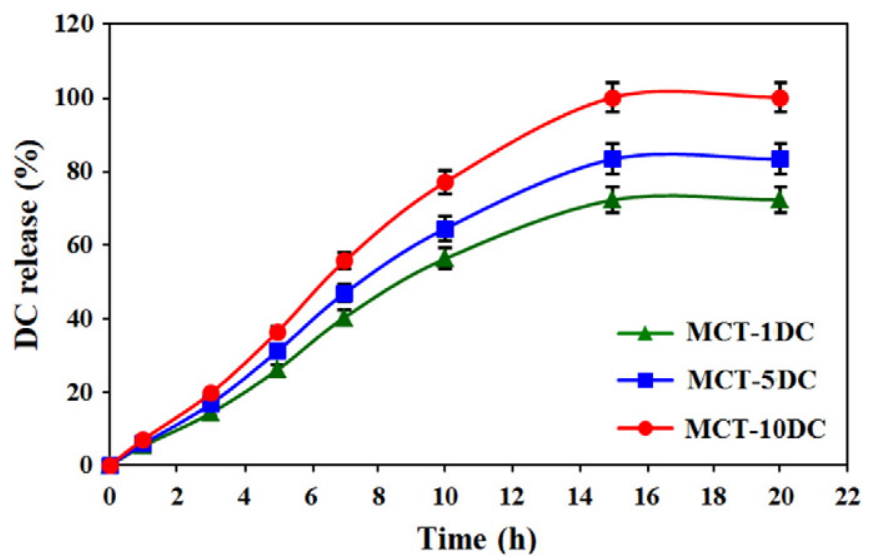

Fig. 5. Drug release behavior MCT-DC composite scaffolds with various doxycycline concentrations.

up to $15 \mathrm{~h}$. The initial increment in drug release in MCT-10 DC scaffold is ascribed to the existence of more contents of DC. However, DC release from all scaffolds was completed within $20 \mathrm{~h}$. In addition, the absorbance of dissolved scaffolds in $\mathrm{HCl}$ solution showed that no sign of DC was observed, representing complete drug release from the scaffolds within $20 \mathrm{~h}$. These results demonstrate a favorable release profile that is suitable for bone infection treatment.

In order to explore the biological efficiency, we have tested antibacterial activity of MCT-DC scaffolds against E. coli and S. aureus bacteria. The localized release of an anti-bacterial agent from the implant, after the constructive surgery, could prevent the bacteria from invading the surgical site and causing severe complications [24]. Hence, DC-loaded MCT scaffolds were used in the present study to provide the scaffolds with antibacterial activity. Fig. 6 shows the zone of inhibition for four MCT and MCT-DC scaffolds at different bacteria strains (Gram positive and Gram negative). The mean size of inhibition ring for MCT, MCT1DC, MCT-5DC and MCT-10DC scaffolds were $1.12 \pm 0.13 \mathrm{~mm}, 1.45 \pm$ $0.16 \mathrm{~mm}, 2.51 \pm 0.23 \mathrm{~mm}$ and $2.95 \pm 0.28 \mathrm{~mm}$ for E-coli respectively (Fig. 6a). As can be seen MCT scaffold also presented antibacterial activity owing to the raise of $\mathrm{pH}$ value throughout its degradation in the bacterial solution. The killing effect of these MCT-DC scaffolds was evidenced by the formation of the inhibition zone in the plate. A similar trend was found for S. aureus (Fig. 6b) since the mean size of inhibition ring increased with escalating the DC concentration, initiating at $1.18 \pm$ $0.14 \mathrm{~mm}$ in MCT, $2.05 \pm 0.21 \mathrm{~mm}$ in MCT-1DC, $2.40 \pm 0.22 \mathrm{~mm}$ in MCT5DC, and reaching $3.54 \pm 0.32 \mathrm{~mm}$ in MCT-10DC. This indicated that the antibacterial activity of MCT-DC in the agar plate against both gram negative (E. coli) and gram positive (S. aureus) bacteria is more than that of pure MCT scaffold. As can be observed in the figure, the bacteria were inhibited to completely grow around the MCT scaffolds containing a higher concentration of DC, while they were proliferated around the bare MCT scaffold. This behavior indicates that there was a relationship between the antibacterial properties of the MCT-DC scaffolds and their DC concentration. As the DC concentration in the MCT scaffolds increased, the inhibition zone became larger in size. This is due to the fact that the MCT scaffold with higher DC concentration was able to release considerably more DC compared to other scaffolds with a lower DC antibiotic content [25].

Fig. $6 c, d$ also show the percentage of bacterial inhibition of all MCT and MCT-DC scaffolds at different incubation times. The MCT scaffold depicts the lowest antimicrobial activity. By contrast, the MCT scaffolds
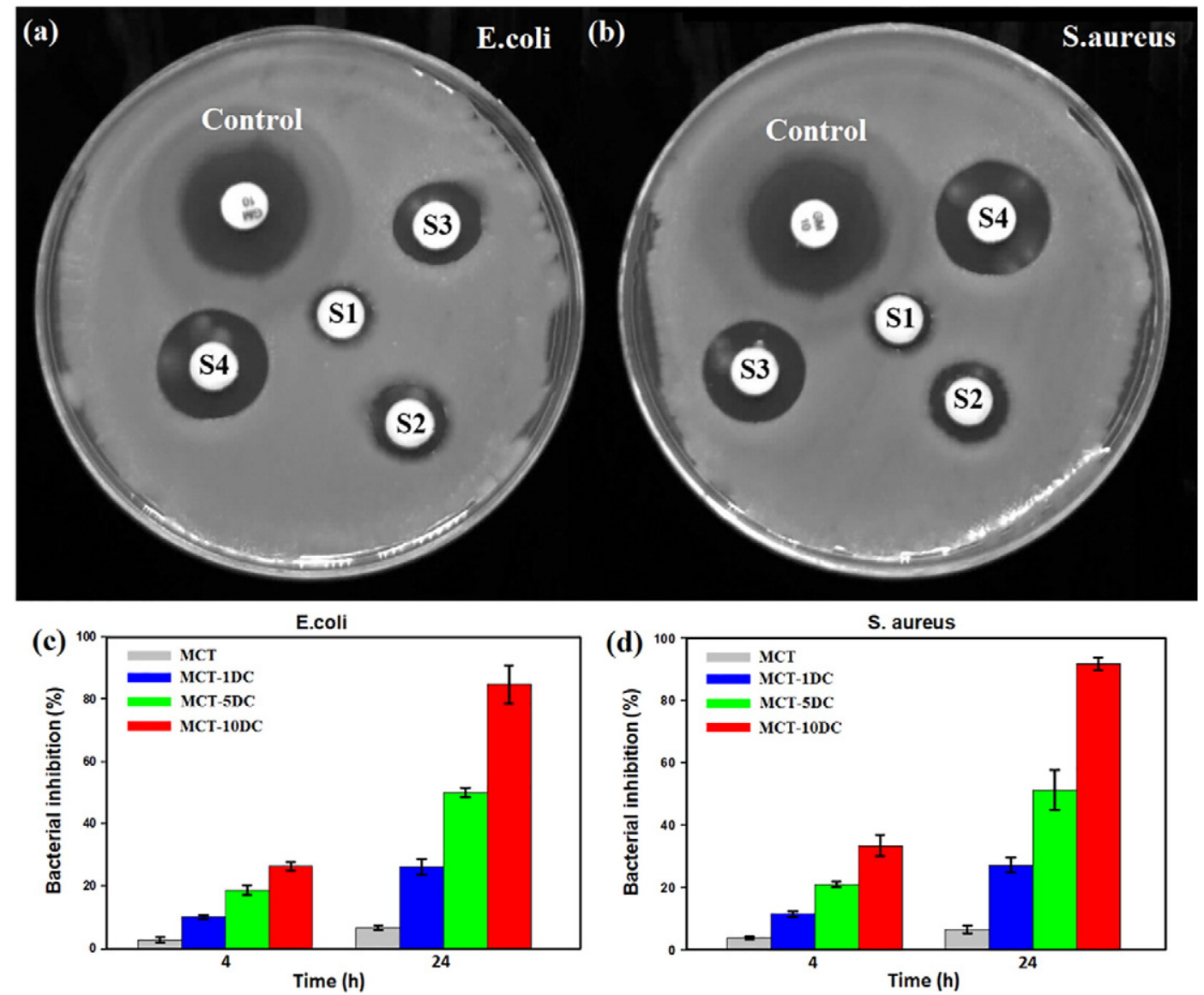

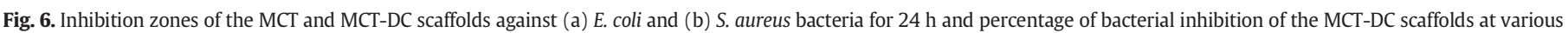
incubation times. Note: (S1): MCT; (S2): MCT-1DC; (S3): MCT-5DC; (S4): MCT-10DC; (Control): gentamicin. 
containing DC effectively inhibit the growth of E. coli and S. aureus. Additionally, the antibacterial activity of the scaffolds increased with the increase of the content of DC. Of all scaffolds, MCT-10DC scaffold showed the highest bacterial inhibition of $84.3 \pm 2 \%$ and $92.5 \pm 3 \%$ after $24 \mathrm{~h}$ incubation in E. coli and S. aureus suspension, respectively. However, the lowest bacterial inhibition was observed for scaffold without DC content. This is attributed to the presence of DC in the MCT scaffolds which acts as a bacterial barrier to prohibit DNA gyrase essential to separating bacterial DNA [25,31], hence reducing cell division.

DAPI staining of cell nuclei on MCT-DC scaffolds after $48 \mathrm{~h}$ of incubation in Fig. 7a-d revealed that on the MCT and MCT-DC scaffolds with low DC content, a large number of cells with spherical shapes were well spread and attached on the outer parts and the surface of the scaffolds, implying suitable cell-scaffold interaction that will lead to osseointegration of the nano particles. However, the cells on the MCT scaffold containing high DC content were poorly-spread, indicating that the scaffolds containing low DC content allow the cells penetrate and migrate within the scaffolds in a manner similar to native ECM. Cytotoxicity of the MCT-DC scaffolds was examined via cell proliferation assay, as can be seen in Fig. 7e. The MTT cell proliferation assay could be employed to test the MCT-DC scaffolds associated cytotoxicity. The concept is that cellular proliferation will decrease considerably in comparison to the control sample in case the MCT-DC scaffolds exert any cytotoxicity. The results of MTT assay conducted on the MCT and MCT-DC scaffolds and control specimens after 24 and 48 days of incubation. The results exhibited that the proliferation of MG63 cells cultured on MCT scaffold slightly declined with escalating the incubation time to
48 days due to more release of the DC drug. The MCT scaffold is able to stimulate the proliferation of osteoblastic-induced bone marrow cells. However, the MCT-DC scaffolds containing low concentration of DC depicted a very slight reduction in cell proliferation, whereas this decline is not sufficient to present any cytotoxic effects. It was also visible that the scaffolds containing high DC content exhibited cytotoxic behavior. Similarly, it was reported [41] that at low DC concentrations $(1 \mu \mathrm{g} / \mathrm{mL})$ there is a proanabolic influences over osteoblastic phenotypic cells, concerning proliferation. While higher DC concentrations $(10 \mu \mathrm{g} / \mathrm{mL})$ have a substantial inhibitory influence in cell growth and $25 \mu \mathrm{g} / \mathrm{mL}$ leads to absence of cell growth.

Formation of apatite on the scaffolds surface throughout the incubation in SBF solution ensures the regeneration of bone in the in-vivo conditions [40]. Due to higher cell viability of MCT and MCT-1DC scaffolds than others, these scaffolds were chosen for evaluation of apatite formation ability. Fig. 8 shows the SEM images of the scaffolds after incubation in the SBF solution for 7 days at $37^{\circ} \mathrm{C}$ to determine the bioactivity of the scaffolds. Different magnifications (Fig. 8a1-4) exhibit that the layer of apatite has been formed on the scaffold surface owing to the direct contact of SBF. It seems that the apatite is also formed on the inner wall of the pores as indicated with arrow (Fig. 8a2 and b2), since the SBF solution has sufficient time to infiltrate inside the scaffold. Moreover, formation of apatite resulted in altering the morphology and size of the pores in the scaffolds. It is worth noting that due to the growth of apatite crystals in the inner wall of the pores, the small pores are filled, hence reducing the pore size which leads to escalating the strength of scaffolds.
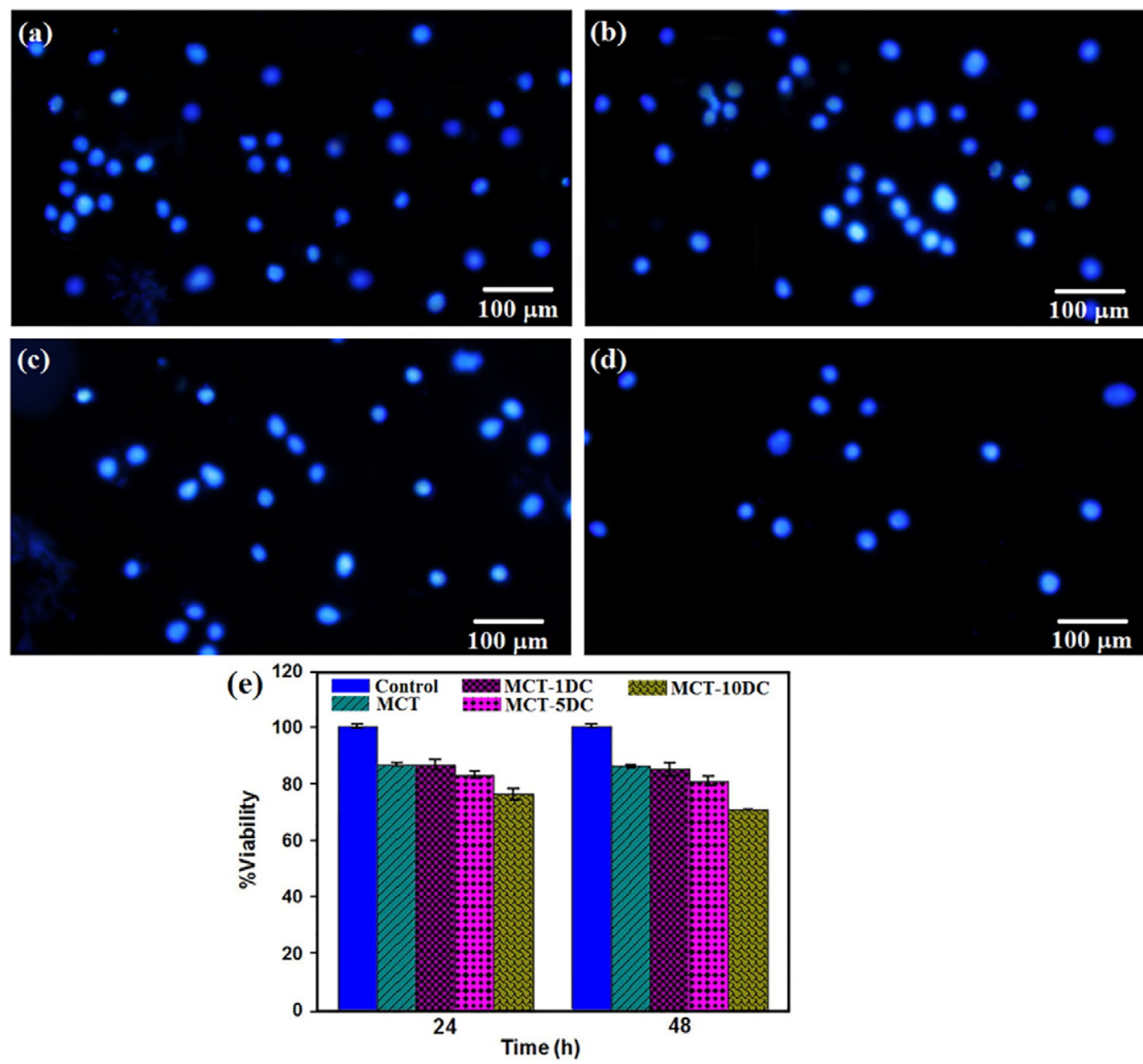

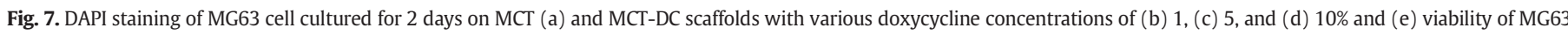
osteoblast cells cultured for 24 and 48 h on MCT-DC scaffolds. 

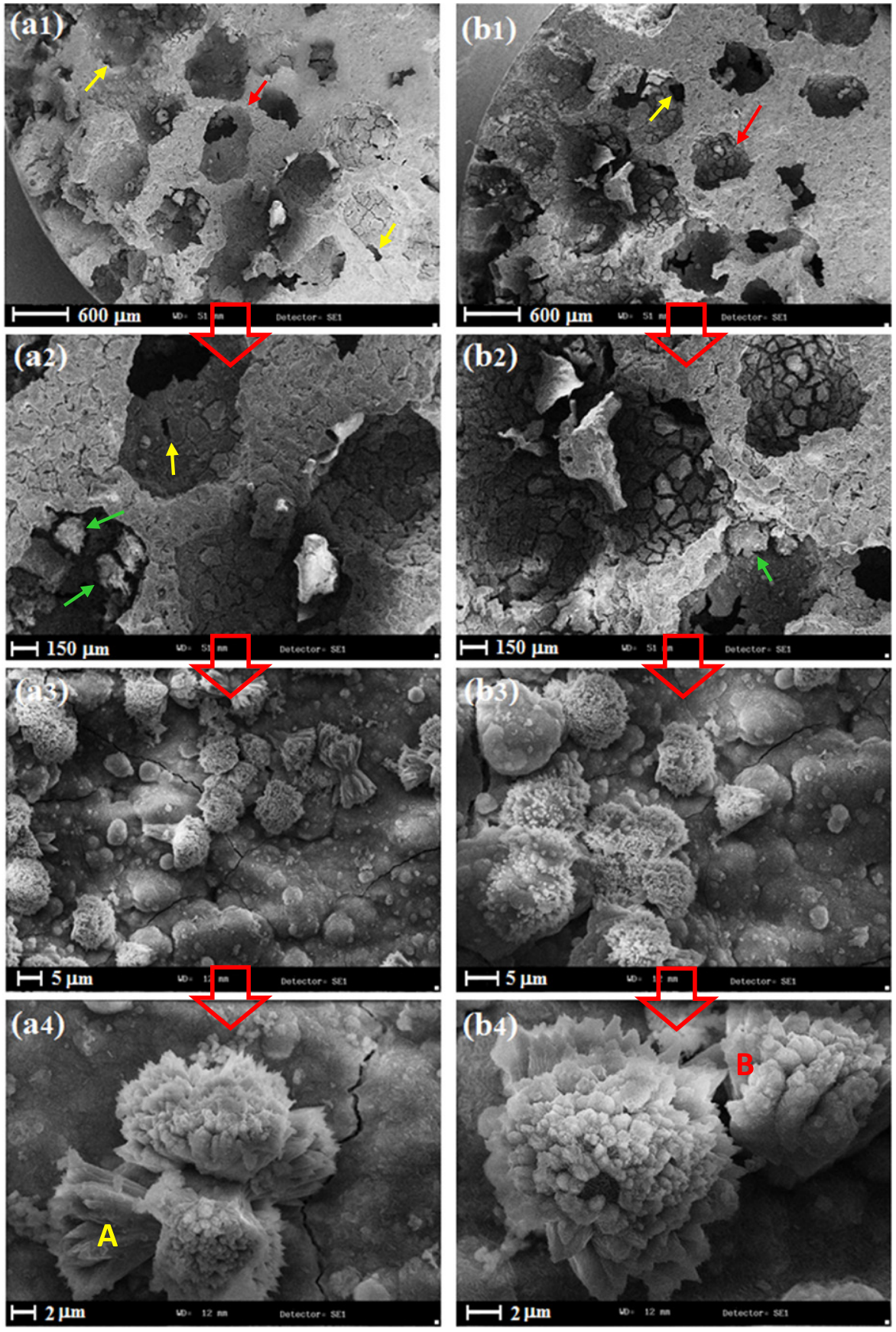

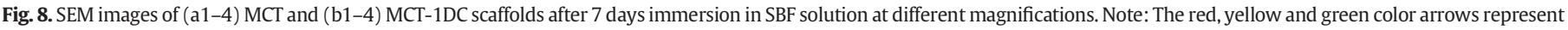
pores, micro-pores and apatite formation in inner wall of the pores, respectively.

High magnifications (Fig. 8a3,4) exhibit that the apatite formed on the scaffolds surface possesses flower-like nano-flakes with an assembled hierarchical structure. Furthermore, there is no significant difference in the HA layer formed on MCT and MCT-1DC scaffolds indicating that DC did not obstruct the bioactivity of MCT (Fig. 8b1-4). The EDS pattern shows the presence of the Mg peak with low intensity and the presence of the calcium, phosphorus, and oxygen with high intensity. Similar products including $\mathrm{Ca}, \mathrm{Mg}, \mathrm{C}, \mathrm{P}$, and $\mathrm{O}$ were observed in the MCT scaffold containing DC, suggesting that the product contains $\mathrm{HA}$ (Fig. 9a). The atomic ratio of $\mathrm{Ca} / \mathrm{P}$ of the product of MCT and MCT-DC scaffolds was about 1.44 and 1.42, respectively, representing the Ca-deficit hydroxyapatite (HA) formation.
Formation of HA represents a high bioactivity and biological performance of the scaffolds since it is a vital precondition for the direct binding of bioactive components to the living bone tissue. The XRD pattern (Fig. 9b) further confirms the result of EDS analysis since MCT and MCT-1DC scaffolds presented the strongest HA and peaks, implying its apatite formation ability in the SBF solution. Broad $\mathrm{Mg}(\mathrm{OH})_{2}$ diffraction peaks can be related to the poor crystallinity of these phases. It was reported [42] that the presence of hydroxides in the corrosion products is a direct evidence of a pitting type of corrosion attack, since hydroxide-based corrosion products can form deep inside the pits and fall off when the corrosion products covering the pits disintegrate from the surface. 

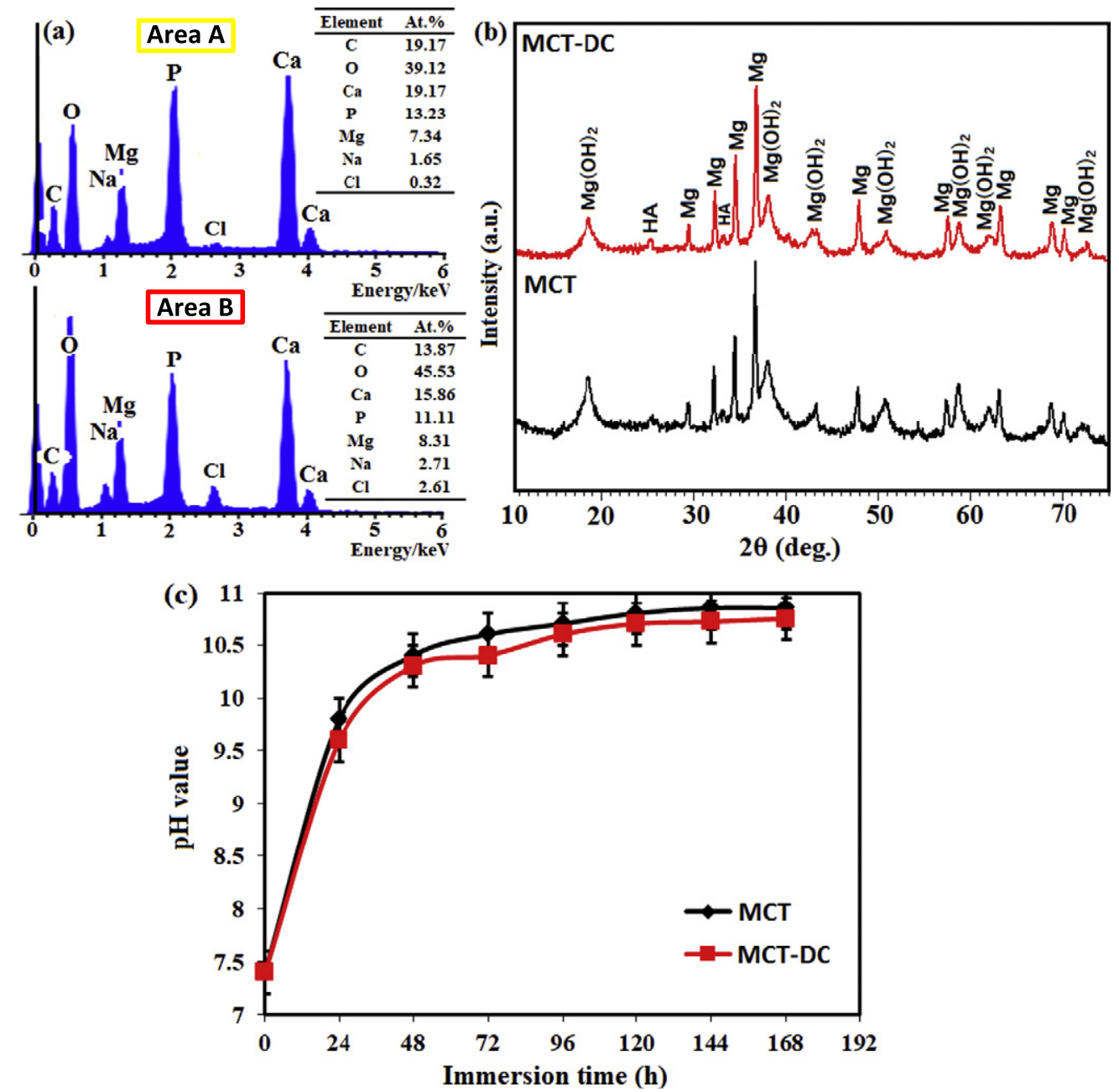

Fig. 9. EDS spectrum of (a) area A and B, and (b) X-ray diffraction patterns and (c) change of pH value of MCT and MCT-1DC scaffolds after 7 days immersion in SBF solution.

In this context, the degradation of MCT scaffolds in the SBF occurred according to the following equation:

$\mathrm{Mg}+2 \mathrm{H}_{2} \mathrm{O}=\mathrm{Mg}(\mathrm{OH})_{2}+\mathrm{H}_{2} \uparrow$

Afterwards through the formation of brucite $\left(\mathrm{Mg}(\mathrm{OH})_{2}\right)$ as a protective layer, the corrosion rate of the scaffold reduce substantially. As a result of the brucite formation, the $\mathrm{CO}_{2}^{3-}, \mathrm{PO}_{3}^{4-}$ and $\mathrm{Cl}^{-}$ions were attracted to the scaffold surface leading to more accumulation of $\mathrm{OH}^{-}$ ion which is crucial for apatite nucleation. In this context, Li et al. [43] showed that undissolved brucite layer on the Mg alloy surface was regarded to accelerate HA nucleation. Subsequently, the nucleation of a HA layer occurs on the scaffold surface, through the reaction of the $\mathrm{PO}_{3}^{4-}$ and $\mathrm{Ca}^{2+}$ ions presence in the SBF. As soon as HA nuclei are formed on the scaffold surface, they are able to grow through consuming $\mathrm{PO}_{3}^{4-}$ and $\mathrm{Ca}^{2+}$ ions from SBF.

Fig. 9c exhibited the $\mathrm{pH}$ values of the SBF solution immersed the MCT and MCT-DC scaffolds at various immersion times. It was shown that when the incubation time was not longer than $24 \mathrm{~h}$, the $\mathrm{pH}$ value elevated rapidly, from 7.4 to 9.7, and subsequently the $\mathrm{pH}$ value became stable at about 10.8. It was assumed that the initial escalation of $\mathrm{pH}$ value was attributed to the accumulation of $\mathrm{OH}$ ion in the form of $\mathrm{Mg}(\mathrm{OH})_{2}$ on the MCT scaffold surfaces $[24,44,45]$. An accelerated pH escalation throughout the initial duration of incubation was reported by numerous in vitro studies [46-48]. The decelerated escalation of $\mathrm{pH}$ at a longer incubation time can be attributed to the deposition of HA on the surface of MCT scaffold. It was worth mentioning that doxycycline was completely released after $20 \mathrm{~h}$ and it has less significant effect on altering the $\mathrm{pH}$ values of the SBF, hence MCT-DC scaffolds showed similar $\mathrm{pH}$ trend with slight differences in the amount of $\mathrm{pH}$ values.

\section{Conclusions}

In this study, novel MCT- $x \mathrm{DC}(x=1,5$ and $10 \%)$ composite scaffolds were prepared via space holder technique as a novel, cost-effective and feasible method with interconnected pores and appropriate corrosion rate and compressive strength. The MCT-DC scaffolds had favorable pores size (600-800 $\mu \mathrm{m})$ with total porosity (65-67\%). The compressive strength (CS) and corrosion density $\left(\mathrm{i}_{\text {corr }}\right)$ of MCT scaffold were in the range of $5 \pm 0.1 \mathrm{MPa}$ and $40.6 \pm 1 \mu \mathrm{A} \cdot \mathrm{cm}^{-2}$, respectively. However, MCT scaffolds loaded with different concentrations of DC show a similar CS and $i_{\text {corr }}$. The results of bioactivity study revealed the apatite formation ability of MCT scaffold loaded with DC. The drug release profiles depicted that the burst and sustained drug release were obtained via DC loading MCT scaffolds and also showed that the drug release rate increased with increasing the DC concentration. Cytotoxicity tests showed that the MCT-DC scaffolds with low concentration of DC did not present toxicity, whereas some toxicity was found in the scaffolds with high DC concentration. All MCT-DC scaffolds exhibited good bactericidal properties against $S$. aureus and $E$. coli bacteria and their antibacterial activities increased with increasing the DC concentration. Thus, MCT-(1-5\%)DC scaffold is an alternative candidate for bone infection treatment. 


\section{Acknowledgments}

The authors would like to thank the Malaysian Ministry of Higher Education (MOHE) and Universiti Teknologi Malaysia for providing the facilities for this research.

\section{References}

[1] M. Yazdimamaghani, M. Razavi, D. Vashaee, K. Moharamzadeh, A.R. Boccaccini, L Tayebi, Porous magnesium-based scaffolds for tissue engineering, Mater. Sci. Eng. C 71 (2017) 1253-1266.

[2] S.-I. Roohani-Esfahani, Y. Chen, J. Shi, H. Zreiqat, Fabrication and characterization of a new, strong and bioactive ceramic scaffold for bone regeneration, Mater. Lett. 107 (2013) 378-381.

[3] R. García-Alvarez, I. Izquierdo-Barba, M. Vallet-Regí, 3D scaffold with effective multidrug sequential release against bacteria biofilm, Acta Biomater. 49 (2017) $113-126$.

[4] Y. Wan, T. Cui, W. Li, C. Li, J. Xiao, Y. Zhu, D. Ji, G. Xiong, H. Luo, Mechanical and biological properties of bioglass/magnesium composites prepared via microwave sintering route, Mater. Des. 99 (2016) 521-527.

[5] Y.F. Zheng, X.N. Gu, F. Witte, Biodegradable metals, Mater. Sci. Eng. R 77 (2014) $1-34$.

[6] L. Zhao, Z. Zhang, Y. Song, S. Liu, Y. Qi, X. Wang, Q. Wang, C. Cui, Mechanical properties and in vitro biodegradation of newly developed porous $\mathrm{Zn}$ scaffolds for biomedical applications, Mater. Des. 108 (2016) 136-144.

[7] X.N. Gu, Y.F. Zheng, A review on magnesium alloys as biodegradable materials, Front. Mater. Sci. Chin 4 (2010) 111-115.

[8] H.R. Bakhsheshi-Rad, M.H. Idris, M.R. Abdul-Kadir, A. Ourdjini, M. Medraj, M. Daroonparvar, E. Hamzah, Mechanical and bio-corrosion properties of quaternary $\mathrm{Mg}-\mathrm{Ca}-\mathrm{Mn}-\mathrm{Zn}$ alloys compared with binary Mg-Ca alloys, Mater. Des. 53 (2014) 283-292.

[9] G. Ryan, A. Pandit, D.P. Apatsidis, Fabrication methods of porous metals for use in orthopaedic applications, Biomaterials 27 (2006) 2651-2670.

[10] Z. Chen, X. Mao, L. Tan, T. Friis, C. Wu, R. Crawford, Y. Xiao, Osteoimmunomodulatory properties of magnesium scaffolds coated with $\beta$-tricalcium phosphate, Biomaterials 35 (2014) 8553-8565.

[11] M. Diba, O.-M. Goudouri, F. Tapia, A.R. Boccaccini, Magnesium-containing bioactive polycrystalline silicate-based ceramics and glass-ceramics for biomedical applications, Curr. Opin. Solid State Mater. Sci. 18 (2014) 147-167.

[12] Y. Bi, Y. Zheng, Y. Li, Microstructure and mechanical properties of sintered porous magnesium using polymethyl methacrylate as the space holder, Mater. Lett. 161 (2015) 583-586.

[13] S.M. Kalantari, H. Arabi, S. Mirdamadi, S.A. Mirsalehi, Biocompatibility and compressive properties of Ti-6Al-4V scaffolds having Mg element, J. Mech. Behav. Biomed. Mater. 48 (2015) 183-191.

[14] T. Hanas, T.S.S. Kumar, G. Perumal, M. Doble, Tailoring degradation of AZ31 alloy by surface pre-treatment and electrospun PCL fibrous coating, Mater. Sci. Eng. C 65 (2016) 43-50.

[15] Z.S. Seyedraoufi, S. Mirdamadi, Synthesis, microstructure and mechanical properties of porous Mg-Zn scaffolds, J. Mech. Behav. Biomed. Mater. 21 (2013) 1-8.

[16] W. Yu, H. Zhao, Z. Ding, Z. Zhang, et al., In vitro and in vivo evaluation of $\mathrm{MgF}_{2}$ coated AZ31 magnesium alloy porous scaffolds for bone regeneration, Colloids Surf., B 149 (2017) 330-340.

[17] S.Z. Khalajabadi, M.R. Abdul Kadir, S. Izman, H.R. Bakhsheshi-Rad, S. Farahany, Effect of mechanical alloying on the phase evolution, microstructure and biocorrosion properties of a $\mathrm{Mg} / \mathrm{HA} / \mathrm{TiO}_{2} / \mathrm{MgO}$ nanocomposite, Ceram. Int. 40 (2014) 16743-16759.

[18] N. Li, Y. Zheng, Novel magnesium alloys developed for biomedical application: a review, J. Mater. Sci. Technol. 29 (2013) 489-502.

[19] H.R. Bakhsheshi-Rad, M.H. Idris, M.R.A. Kadir, S. Farahany, Microstructure analysis and corrosion behavior of biodegradable Mg-Ca implant alloys, Mater. Des. 33 (2012) 88-97.

[20] N.T. Kirkland, N. Birbilis, J. Walker, In-vitro dissolution of magnesium-calcium binary alloys: clarifying the unique role of calcium additions in bioresorbable magnesium implant alloys, J. Biomed. Mater. Res. B 95 (2010) 91-100.

[21] L.C. Córdoba, M.F. Montemor, T. Coradin, Silane/TiO ${ }_{2}$ coating to control the corrosion rate of magnesium alloys in simulated body fluid, Corros. Sci. 104 (2016) 152-161.

[22] P. Amaravathy, S. Sathyanarayanan, S. Sowndharya, N. Rajendran, H.A. Bioactive $\mathrm{TiO}_{2}$ coating on magnesium alloy for biomedical applications, Ceram. Int. 40 (2014) 6617-6630.

[23] V. Antoci Jr, C.S. Adams, J. Parvizi, H.M. Davidson, R.J. Composto, et al., The inhibition of Staphylococcus epidermidis biofilm formation by vancomycin-modified titanium alloy and implications for the treatment of periprosthetic infection, Biomaterials 29 (2008) 4684-4690.
[24] Ł. Rumian, H. Tiainen, U. Cibor, M.K. Borkowicz, M.B. Włoch, H.J. Haugen, E. Pamuła, Ceramic scaffolds with immobilized vancomycin-loaded poly(lactide-co-glycolide) microparticles for bone defects treatment, Mater. Lett. 190 (2017) 67-70.

[25] M. Parent, A. Magnaudeix, S. Delebassée, E. Sarre, E. Champion, M. Viana Trecant, C. Damia, Hydroxyapatite microporous bioceramics as vancomycin reservoir: antibacterial efficiency and biocompatibility investigation, J. Biomater. Appl. 31 (2016) 488-498.

[26] M.H. Alkhraisat, C. Rueda, J.C. Azama, J.L. Aparicio, F.T. Mariño, JT García-Denche, L.B. Jerez, U. Gbureck, E.L. Cabarcos, Loading and release of doxycycline hyclate from strontium-substituted calcium phosphate cement, Acta Biomater. 6 (2010) 1522-1528.

[27] N. Mederle, S. Marin, M.M. Marin, E. Danila, O. Mederle, M.G. Albu Kaya, M.V. Ghica, Innovative biomaterials based on collagen-hydroxyapatite and doxycycline for bone regeneration, Adv. Mater. Sci. Eng. 2016 (5) (2016).

[28] F. Witte, H. Ulrich, C. Palm, E. Willbold, Biodegradable magnesium scaffolds: Part II: peri-implantbone remodeling, J. Biomed. Mater. Res. A 81A (2007) 757-765.

[29] M.P. Staiger, I. Kolbeinsson, N.T. Kirkland, T. Nguyen, G. Dias, T.B.F. Woodfield, Synthesis of topologically-ordered open-cell porous magnesium, Mater. Lett. 64 (2010) 2572-2574.

[30] H. Ghomi, R. Emadi, S.H. Javanmard, Fabrication and characterization of nanostructure diopside scaffolds using the space holder method: effect of different space holders and compaction pressures, Mater. Des. 91 (2016) 193-200.

[31] S. Wang, F. Zheng, Y. Huang, Y. Fang, M. Shen, M. Zhu, X. Shi, Encapsulation of amoxicillin within laponite-doped poly(lactic-co-glycolic acid) nanofibers: preparation, characterization, and antibacterial activity, ACS Appl. Mater. Interfaces 4 (2012) 6393-6401.

[32] G.K. Williamson, W.H. Hall, X-ray line broadening from filed aluminium and wolfram, Acta Metall. 1 (1953) 22-31.

[33] Y.T. Sul, Osseoinductive Magnesium-Titanate Implant and Method of Manufacturing the Same. United State Patent. Patent no.: US 7, 452, 566 B2, 2008.

[34] M. Kheradmandfard, M.H. Fathi, Preparation and characterization of Mg-doped fluorapatite nanopowders by sol-gel method, J. Alloys Compd. 504 (2010) 141-145.

[35] A.M.D'. 1ez-Pascual, A.L.D'. 1ez-Vicente, Effect of $\mathrm{TiO}_{2}$ nanoparticles on the performance of polyphenylsulfone biomaterial for orthopaedic implants, J. Mater. Chem. B 2 (2014) 7502-7514.

[36] K. Kavitha, S. Sutha, M. Prabhu, V. Rajendran, T. Jayakumar, In situ synthesized novel biocompatible titania-chitosan nanocomposites with high surface area and antibacterial activity, Carbohydr. Polym. 93 (2013) 731-739.

[37] S.K. Bajpai, Mamta Jadaun, M. Bajpaia, Pooja Jyotishi, et al., Controlled release of Doxycycline from gum acacia/poly(sodium acrylate) microparticles for oral drug delivery, Int. J. Biol. Macromol. 104 (2017) 1064-1071.

[38] H.F.O. Silva, K.M.G. Lima, M.B. Cardoso, et al., Doxycycline conjugated with polyvinylpyrrolidone-encapsu lated silver nanoparticles: a polymer's malevolent touch against Escherichia coli, RSC Adv. 5 (2015) 66886-66893.

[39] L.A. Moura, F.V. Ribeiro, T.B. Aiello, E.A. Duek, Characterization of the release profile of doxycycline by PLGA microspheres adjunct to non-surgical periodontal therapy, J. Biomater. Sci. Polym. Ed. 26 (2015) 573-584

[40] S. Hoover, S. Tarafder, A. Bandyopadhyay, S. Bose, Silver doped resorbable tricalcium phosphate scaffolds for bone graft applications, Mater. Sci. Eng. C 79 (2017) 763-769.

[41] P.S. Gomes, M.H. Fernandes, Effect of therapeutic levels of doxycycline and minocycline in the proliferation and differentiation of human bone marrow osteoblastic cells, Arch. Oral Biol. 52 (2007) 251-259.

[42] D. Sachdeva, Insights into microstructure based corrosion mechanism of high pressure die cast AM50 alloy, Corros. Sci. 60 (2012) 18-31.

[43] Z. Li, X. Gu, S. Lou, Y. Zheng, The development of binary Mg-Ca alloys for use as biodegradable materials within bone, Biomaterials 29 (2008) 1329-1344.

[44] P. Qi, Y. Yang, S. Zhao, J. Wang, et al., Improvement of corrosion resistance and biocompatibility of biodegradable metallic vascular stent via plasma allylamine polymerized coating, Mater. Des. 96 (2016) 341-349.

[45] C.Z. Zhang, S.J. Zhu, L.G. Wang, R.M. Guo, G.C. Yue, S.K. Guan, Microstructures and degradation mechanism in simulated body fluid of biomedical $\mathrm{Mg}-\mathrm{Zn}-\mathrm{Ca}$ alloy processed by high pressure torsion, Mater. Des. 96 (2016) 54-62.

[46] H.R. Bakhsheshi-Rad, E. Hamzah, A.F. Ismail, et al, Synthesis of a novel nanostructured zinc oxide/baghdadite coating on $\mathrm{Mg}$ alloy for biomedical application: invitro degradation behavior and antibacterial activities, Ceram. Int. 43 (2017) $14842-14850$

[47] H.R. Bakhsheshi-Rad, E. Hamzah, George J. Dias, Safaa N. Saud, F. Yaghoubidoust, Z. Hadisi, Fabrication and characterisation of novel ZnO/MWCNT duplex coating deposited on Mg alloy by PVD coupled with dip-coating techniques, J. Alloys Compd. 728 (2017) 159-168.

[48] H.R. Bakhsheshi-Rad, E. Hamzah, M. Kasiri-Asgarani, S. Jabbarzare, M. Daroonparvar, A. Najafinezhad, Fabrication, degradation behavior and cytotoxicity of nanostructured hardystonite and titania/hardystonite coatings on Mg alloys, Vacuum 129 (2016) 9-12. 